\title{
Combined soil washing and CDEO for the removal of atrazine from soils
}

\author{
Elisama Vieira ${ }^{1}$, Cristina Sáez ${ }^{2}$, Carlos A. Martínez-Huitle ${ }^{1, *}$, \\ Pablo Cañizares ${ }^{2}$, M. A. Rodrigo ${ }^{2}$ \\ ${ }^{1}$ Institute of Chemistry, Federal University of Rio Grande do Norte, Lagoa Nova CEP 59078-970, \\ Natal, RN, Brazil \\ ${ }^{2}$ Department of Chemical Engineering. Enrique Costa Building. Campus Universitario s/n. 13071 \\ Ciudad Real. Spain
}

\begin{abstract}
In this work, it is studied the removal of atrazine from spiked soils by soil washing using surfactant fluids, followed by the treatment of the resulting washing waste by electrolysis with boron doped diamond anode. Results confirm that combination of both technologies is efficient for the removal and total mineralization of atrazine. Ratio surfactant/soil is a key parameter for the removal of atrazine from soil and influences significantly in the characteristic of the wastewater produced, affecting not only to the total organic load but also to the mean size of micelles. The higher the ratio surfactant soil, the lower is the size of the particles. Electrolyses of this type of waste attain the complete mineralization. TOC and COD are removed from the start of the treatment but the key of the treatment is the reduction in size of the micelles, which lead to a higher negative charge in the surface and to the faster depletion of the surfactant as compared with the pesticide.
\end{abstract}

\section{Keywords}

Pesticide, soil remediation, surfactant, soil washing, conductive diamond, electrolysis

\section{Highlights}

- Sequential soil washing - washing waste electrolysis is an efficient treatment for the depletion of atrazine from polluted soils 
- Ratio surfactant /soil influences on the characteristic of the waste produced during the treatment affecting to the size of micelles and organic load.

- Electrolysis with diamond anodes can attain the depletion of pollutants from soils washing wastes, regardless of the ratio surfactant/soil used in the soil washing

- Electrolysis of soil washing fluids proceed though the reduction in size of micelles till their complete depletion

- Sulphate ions release from the oxidation of SDS play an important role in the oxidation process 


\section{Introduction}

Nowadays, soil remediation has become an environmental matter of the major importance [1-3]. In addition to the negative impact on the ecosystems, transport of pollutant to water reservoirs may decrease the quality and even prevent its use for human supply. For this reason, it is very important the rapid actuation against accidental discharges of hazardous species with efficient technologies that remediate the soil rapidly and avoids diffuse pollution. One of these technologies is soil washing [4-6]. It consists on the extraction of pollutants contained in the soil with a solution that helps to obtain an efficient transfer of the pollution from the soil to a liquid phase. It is an off-site technology, which requires digging and processing of soil in special extractor units. In fact, it can be considered as a soil-liquid extraction operation unit, in which the pollutant is transferred from the solid soil to the liquid washing fluid. In the case of organics, the use of surfactant solutions is the most extended application. Using this operation, soil can be completely remediated from the chemical point of view. However, a highly polluted waste is obtained with a high organic load and complex mixture of pollutants consisting of dissolved organic pollutant, surfactant and micelles (with both species), in addition to the inorganic salts dissolved and exchanged from the soil during the extraction process.

In order to treat this waste, efficient technologies have to be used. Electrolysis with diamond electrodes has become a reference in the recent years [7-10], because of its great robustness and efficiency. It may attain the total removal of pollution by mineralization and to the knowledge of the authors of this manuscript, and based on the huge amounts of results presented in the literature, there are no refractory species to this treatment. Its high efficiency is associated to the production of many types of oxidant species from hydroxyl radicals formed by water electrolysis to peroxocompounds formed directly and by mediated oxidation of sulphate, phosphate, carbonates 
and even carboxylic acids on the surface of the diamond electrode or by attack of hydroxyl radicals. Decomposition of these oxidants, forming hydrogen peroxide and other paths that promotes the formation of ozone completes the cocktail of oxidants. This mixture is responsible for extending the oxidation from the nearness of the anode surface to the bulk of the waste, promoting the oxidation of pollutants by different mechanisms. The target wastewater for this treatment is medium-to-highly polluted waste with COD within the range 1500-20000 $\mathrm{mg} \mathrm{dm}^{-3}$ [7], for which efficiency in the use of electricity of $100 \%$ is typically obtained. For lower concentration of COD, mass transport limitations control the oxidation rate and efficiency is drastically reduced. The combination of electrolysis with other technologies, such as the Fenton oxidation [11-19] or the irradiation of ultrasound [20] or UV light [21] [22] that promotes the activation of oxidants produced electrodically by producing more efficient radicals, is the best way to keep efficiency of this treatment in high values.

Pollution of soils with pesticides is a problem of the major importance. Pollution may come from accidental discharge or from the excessive use of pesticide and the environmental impact is usually very high[1]. Atrazine is one of the most applied pesticides and it has been the focus of several researches[12, 23-28] because of its low biodegradability, long half-life and low solubility in water (33 $\mathrm{mg} \mathrm{dm}^{-3}$ at $22^{\circ} \mathrm{C}$ ). This work aims to evaluate the effectiveness of a complete treatment of a soil spiked with atrazine, consisting of the soil washing with a sodium dodecyl sulphate solution followed by the electrolysis with BDD anodes of the resulting wastewater. Effect of the ratio surfactant /soil is going to be assessed trying to determine is influence in the soil washing efficiency and in the characteristics of the washing waste. 


\section{Experimental methodology}

In this work, kaolinite was selected as model soil. This material is not reactive and it has a low hydraulic conductivity, low cation exchange capacity and zero organic content [29-31]. The atrazine was selected as a model organic compound and it was obtained from Fluka. Sodium dodecyl sulphate (SDS) was used as a solubilizing agent (supply by Panreac). $\mathrm{NaHCO}_{3}(96 \%)$ was also obtained from Panreac.

Preparation of spiked soil. Samples of polluted soil were prepared by dissolving atrazine in hexane and then mixing this atrazine/hexane solution with kaolinite. The spiked clay was aerated during 1 day to favor evaporation of the hexane and, in this way, the atrazine was homogeneously distributed on the clay surface. This method has been described in the literature by different authors [4] [31] [30]. The resulting atrazine concentration in the soil was around $100 \mathrm{mg} \mathrm{kg}^{-1}$ of soil.

Soil washing procedure. Soil washing with surfactant fluid solution was carried out in a stirred tank operated in discontinuous mode. The tank volume was $1000 \mathrm{~cm}^{3}$. Low-permeability soil (1000 g) polluted with $100 \mathrm{mg}$ atrazine $\mathrm{kg}^{-1}$ of soil and $800 \mathrm{~cm}^{3}$ of solubilizing agent (containing deionized water, $500 \mathrm{mg} \mathrm{dm}^{-3}$ of $\mathrm{NaHCO}_{3}$, and concentrations of sodium dodecyl sulphate (SDS) surfactant ranging from 100 to $5000 \mathrm{mg} \mathrm{dm}^{-3}$ were mixed in the reactor for $6 \mathrm{~h}$ at a stirring rate of $120 \mathrm{rpm}$. The same tank then acted as a settler (during $24 \mathrm{~h}$ ) to separate the soil from the effluent. These effluents consisted of aqueous mixtures of atrazine and surfactants, which become the influent of the electrolytic treatment.

Electrochemical oxidation of the soil washing effluents. Electrochemical oxidation experiments were carried out in a bench-scale plant with a single-compartment electrochemical flow. Bulk 
oxidations were performed in a single-compartment cell, as described in previous works [5]. BDD and steel electrodes were used as anode and cathode, respectively. Characteristic of BDD are as follows: $\mathrm{sp}^{3} / \mathrm{sp}^{2}$ ratio: 225 ; boron content: $500 \mathrm{ppm}$; width of the diamond layer: $2.68 \mu \mathrm{m}$. For the electrochemical flow cell, inlet and outlet were provided for effluent circulation through the reactor; the simulated effluent was stored in a thermo-regulated glass tank $\left(1000 \mathrm{~cm}^{3}\right)$ and circulated through the cell using a peristaltic pump at a flow rate of $200 \mathrm{dm}^{3} \mathrm{~h}^{-1}$. The electrical current was applied using a DC Power Supply (FA-376 PROMAX). Temperature was kept constant by means of a water bath.

Analyses. The atrazine concentration in the liquid phase was determined using an $\mathrm{L}-\mathrm{L}$ extraction process. This process was carried out in separator flasks of $100 \mathrm{dm}^{3}$ using ethyl acetate/hexane as extraction solvent (ratio atrazine solution/solvent $=0.33 \mathrm{v} / \mathrm{v}$ ). All samples extracted from electrolyzed solution were filtered with $0.25 \mu \mathrm{m}$ nylon Whatman filters before analysis. The concentrations of the compounds were quantified by HPLC (Agilent 1100 series) using analytical column Phenomenex Gemini $5 \mu \mathrm{m}$ C18. The detection wavelength of $223 \mathrm{~nm}$ was used and the temperature oven was maintained at $25^{\circ} \mathrm{C} .20 \mu \mathrm{L}$ aliquots were injected, using as mobile phase, a mixture of acetonitrile/water $(45: 55(\mathrm{v} / \mathrm{v}))$ at $0.3 \mathrm{~cm}^{3} \mathrm{~min}^{-1}$. The total organic carbon (TOC) concentration was monitored using a Multi N/C 3100 Analytik Jena analyser. The atrazine and surfactant removal were monitored through the COD content during electrolysis using a $\mathrm{HACH}$ DR2000 analyzer. Zeta potential was also measured for the clarified liquid using a Zetasizer Nano ZS (Malvern, UK). Measurements of $\mathrm{pH}$ were carried out with an InoLab WTW pH-meter. The particle size was monitored during electrochemical oxidation with a Mastersizerhydro 2000SM (Malvern). The colorimetric method used to determine the concentration of the SDS surfactant has been reported by Jurado et al. [32]. 


\section{Results and Discussions}

Soil washing. From the viewpoint of a chemical engineer, soil washing is a solid-liquid extraction operation unit, for which it is known that temperature and ratio between extracting agent and solid are the two key parameters in order to obtain an efficient treatment. In a full-scale soil washing application, regulation of temperature is not going to be a suitable choice, because of the expected high cost (due to the expected high amounts of soil to be processed). Hence, temperature will be kept at ambient conditions and the key parameter in the remediation of a soil by washing with a surfactant solution is the ratio surfactant/soil. Taking into account this fact, Figure 1 shows the concentration of SDS and atrazine in the soil after applying the washing treatment with different surfactant/soil ratios. As it can be observed, both the pollutant and the surfactant are removed efficiently from the soil with this treatment and no significant differences are seen in the concentration of SDS and atrazine with increasing the ratio surfactant/soil.

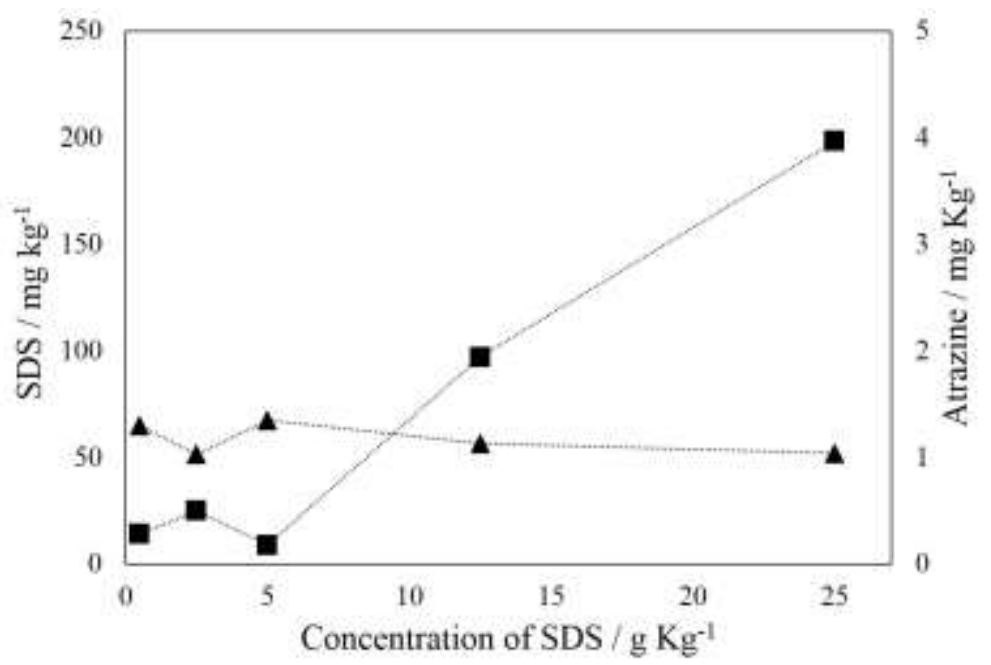

Figure 1. Surplus concentration of SDS and atrazine after the soil washing treatment

These results demonstrate that even low concentrations of SDS can be sufficient to extract efficiently all the pollution contained in the soil. Maximum removals of atrazine can be attained 
with ratios as low as $0.5 \mathrm{~g}$ surfactant $/ \mathrm{kg}$ soil and no significant differences are obtained within the range $0.5-25.0$ in the treated soil quality. However, the resulting waste coming from the washing fluid is expected to have different characteristics and hence its later treatment by electrolysis may be strongly influenced by them. Figure 2 shows the main characteristic of the effluents produced in this treatment.
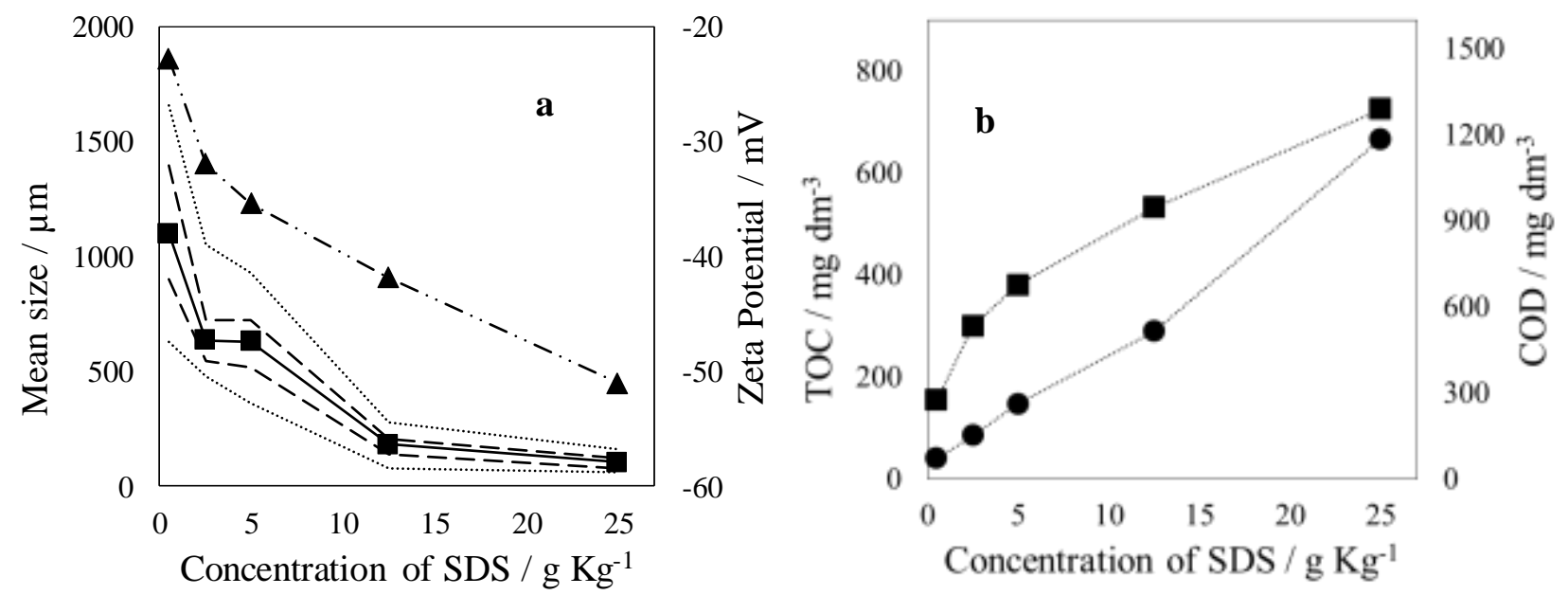

Figure 2. Soil-washing effluent polluted with atrazine. (a) z-potential( $\boldsymbol{\Delta})$, mean particle size( $\boldsymbol{\square})$, size limits including $50 \%$ of the particles(- $(-)$, size limits including $80 \%$ of the particles $(\cdots \cdots \cdots)$. (b) TOC and COD profiles at different ratios SDS/soil.

The higher the ratio surfactant/soil, the higher is the pollution of the effluent (in terms of COD and TOC), because of the higher content in surfactant of the washing fluid. In addition, the nature of the wastewater produced differs completely. Low concentrations of surfactant lead to the formation of big micelle particles (pesticide micro-drops covered by a layer of surfactant) with a low negative charge and a high dispersion in the size of particles. In increasing the amount of surfactant, the size of the particles decreases and the superficial charge becomes more negative, meanwhile the dispersion in the size range decreases. 
Electrolysis of the soil washing effluent. Figure 3 shows the changes in the mean particle size and z-potential during the galvanostatic electrolysis of the five soil washing effluents using BDD anodes and applying $30 \mathrm{~mA} \mathrm{~cm}^{-2}$ at $25^{\circ} \mathrm{C}$.
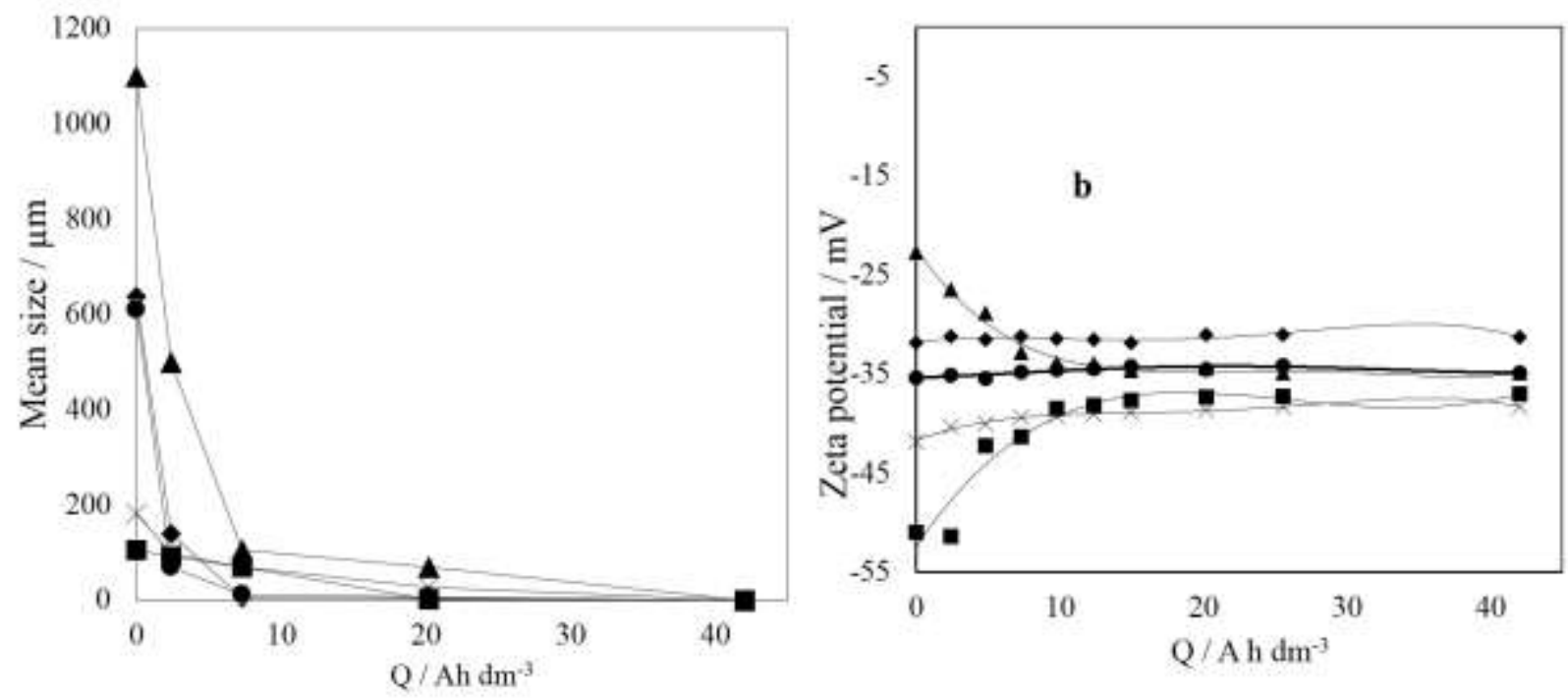

Fig. 3. Changes in the mean particle size (a) and z-potential (b) during the electrolysis at j: $30 \mathrm{~mA}$ $\mathrm{cm}^{-2}$ of the effluents produced during soil washing with the following [SDS]/soil ratios: $0.5(\mathbf{\Delta})$, $2.5(\bullet), 5.0(\bullet), 12.5(\mathrm{x})$ and 25.0

In applying electric charge, the size of the micelles decreases down to the detection limits of the equipment, following an exponential trend. This is a very interesting process that to the authors' knowledge has not been studied before and it may have a great significance in the design of full size electrolytic processes. Due to steric concerns, direct electrolysis is not expected to develop but mediated oxidation from oxidants produced on the anode surface. As expected, the higher the amount of surfactant, the higher is the resulting electric charge required for the removal of the particulate pollutant, although there is not a direct relationship between both parameters and rate seems to be increased for larger particles. Regarding the superficial charge of the micelles, the initial situation is very different in the five effluents studied but z-potential allows us to observe that 
during the treatment, the charge of the particles tends to a value around $-30 \pm 5 \mathrm{mV}$ as the size of the particles decrease. This trend is indicative of the highly complex regrouping processes of surfactant in the micelles during the electrolysis because the initial z-potential of the five wastes was higher (in absolute value) for the wastes containing smaller particles and lower for the wastes containing bigger micelles. Superficial charge of the smaller micelles formed during electrolysis does not seem to be related only to the size of the micelles as in the soil washing process but to much more complex processes, which may suggest the influence of oxidants electrogenerated on these surfaces.

Figure 4 shows the changes in the concentration of surfactant and pesticide during the electrolysis of soil washing effluents.
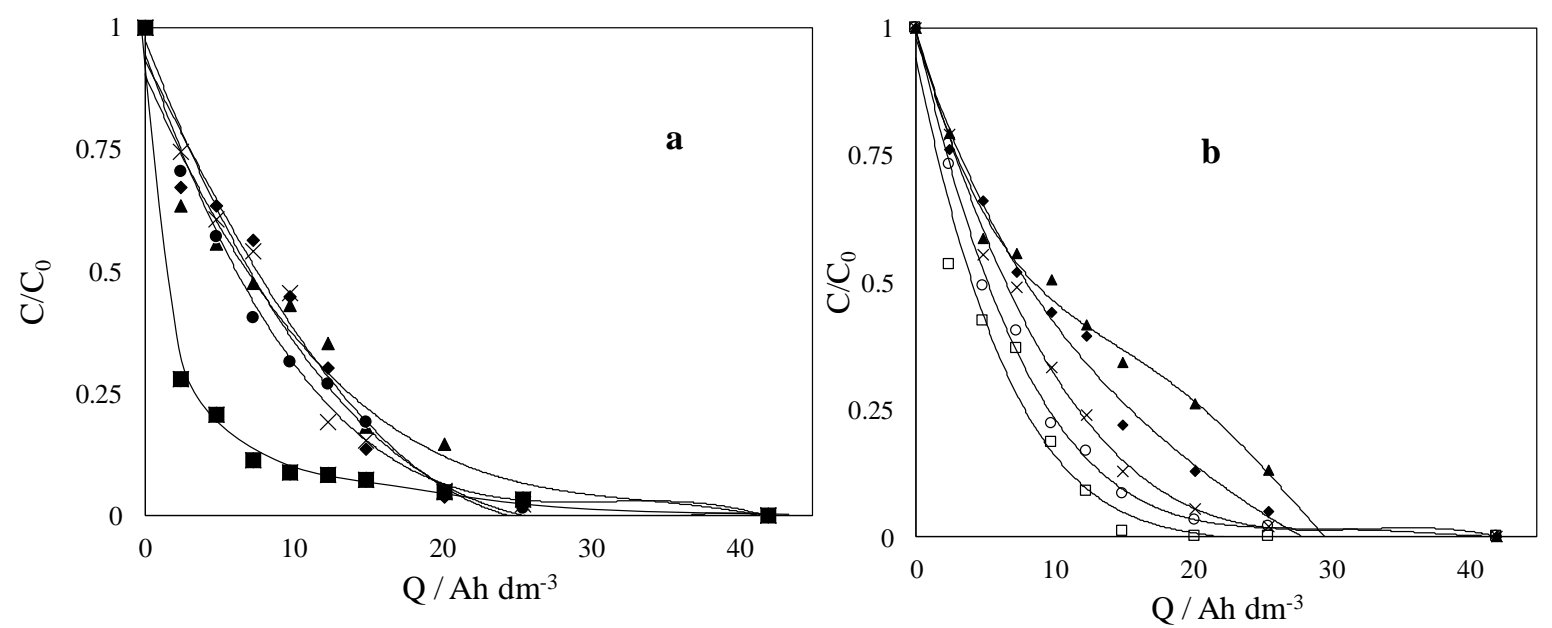

Fig. 4. SDS (a) and atrazine (b) removal profiles during the electrolysis at $\mathrm{j}: 30 \mathrm{~mA} \mathrm{~cm} \mathrm{co}^{-2}$ the effluents produced during soil washing with the following [SDS]/soil ratios: $0.5(\boldsymbol{\Delta}), 2.5(\bullet), 5.0$ $(\bullet), 12.5(\mathrm{x})$ and $25.0(\mathbf{\square})$.

In comparing profiles, it can be clearly seem that surfactant is removed faster than pesticide. This behaviour is in agreement with the progressive reduction in the size of the micelles during the treatment and it indicates that the removal of pollution proceeds though the attack of oxidants to the 
surface of the micelles where SDS is protecting the pesticide. However, the simultaneous oxidation of pesticide (most probably when dissolved from the micelles) and mineralization clearly indicates that pesticide and reaction intermediates are also attacked are completely oxidized up to carbon dioxide. Dissolution of pesticide in water is a key factor in explaining the results and it has to be taken into account that atrazine is no completely insoluble in water but a significant solubility is expected (solubility in water is $33 \mathrm{mg} \mathrm{dm}^{-3}$ ). Regarding intermediates produced, Table 1 shows the maximum area of the three intermediates detected according to the HPLC. They are completely depleted during the electrolysis and as it can be observed, the lower the SDS concentration, the higher is the maximum concentration of intermediates detected. This fact indicates that degradation of the larger micelles lead to the formation of higher concentration of intermediates, although it does not influence on the oxidation mechanism.

Table 1. Maximum concentration of intermediates measured during the electrolysis of the soil washing efluents

\begin{tabular}{|c|c|c|c|}
\hline $\mathrm{SDS} / \mathrm{g} \mathrm{Kg}^{-1}$ & $\begin{array}{c}\text { Intermediate } 1 \\
(2.41 \mathrm{~min})\end{array}$ & $\begin{array}{c}\text { Intermediate } 2 \\
(4.01 \mathrm{~min})\end{array}$ & $\begin{array}{c}\text { Intermediate 3 } \\
(5.12 \mathrm{~min})\end{array}$ \\
\hline 0.5 & 2531 & 956 & 854 \\
\hline 2.5 & 1745 & 1012 & 508 \\
\hline 5 & 1898 & 853 & 612 \\
\hline 12.5 & 893 & 645 & 573 \\
\hline 25 & 965 & 698 & 386 \\
\hline
\end{tabular}

Fig. 5 shows the changes of TOC and COD during the five electrolyses. The complete oxidation (COD removal) and mineralization (TOC removal) of the waste is obtained regardless of the initial concentration of surfactant. The electrical charge required for depletion does not differ significantly from one effluent to the other, because the removal of the effluents with the higher organic content (coming from the application of a higher surfactant/soil ratio in the soil washing) is very efficient. Another important point it the plateau zone observed in the TOC vs. Q plots (zoomed in the onset). This plateau was previously observed in the treatment of other pollutants with low solubility [33- 
35] and could be explained by competing oxidation reactions between the raw pollutant and the intermediates caused by the great differences in their oxidazability.
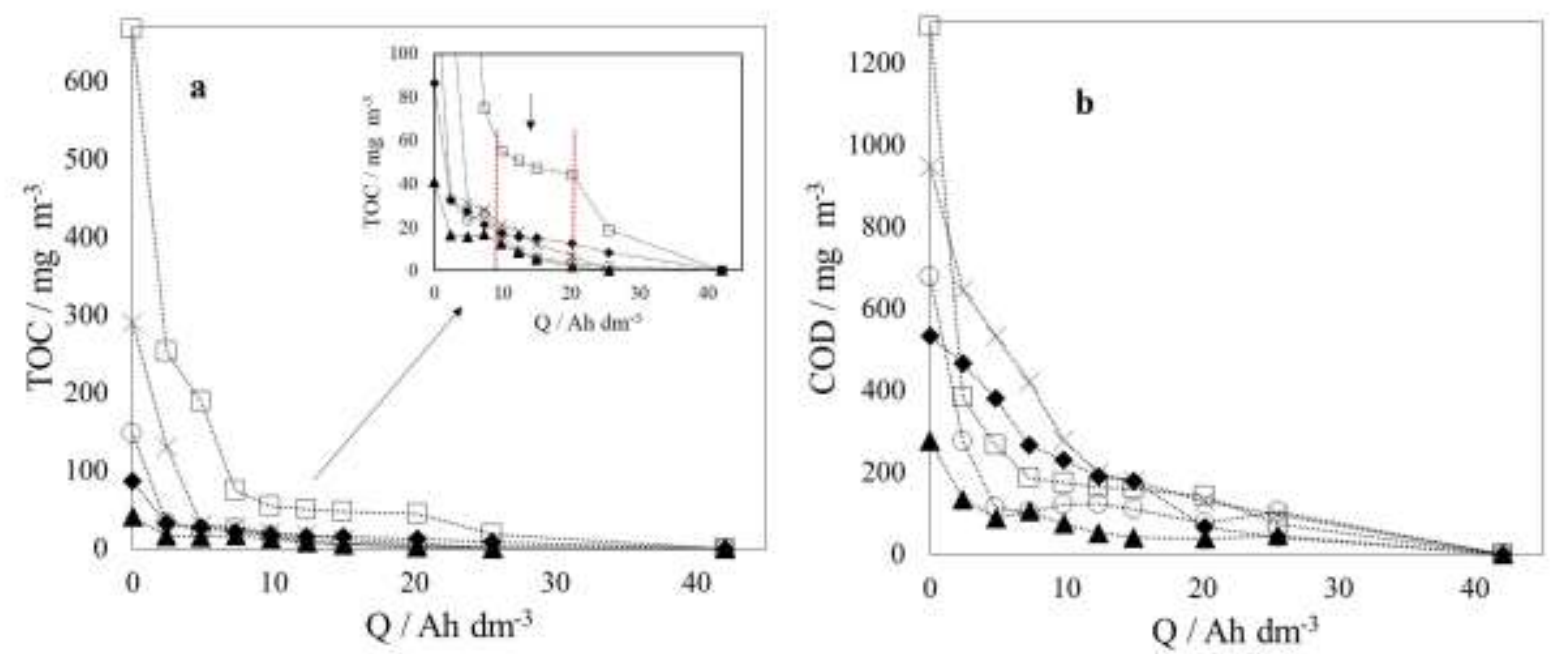

Figure 5. TOC and COD removal profiles during electrolysis at $\mathrm{j}: 30 \mathrm{~mA} \mathrm{~cm}{ }^{-2}$ of the effluents produced during soil washing with the following $[\mathrm{SDS}] /$ soil ratios: $0.5(\mathbf{\Delta}), 2.5(\bullet), 5.0(\bullet), 12.5$ $(\mathrm{x})$ and $25.0(\mathbf{\square})$.

Taking into account the composition of the soil washing fluid (only carbonates and bicarbonates are present as ionic species), initially only peroxocarbonates and products coming from the decomposition of these species (mainly hydrogen peroxide) are expected to be produced in the reaction media [36]. However, the degradation of SDS may also be related to the production of a very efficient oxidant: the peroxosulphate. Thus, there is a significant release of sulphate when the surfactant is oxidized. This release can explain the further expected oxidation of this anion to peroxosulphate, which could be playing a very important role in the overall oxidation process [37, 38]. Figure 6 shows the concentration of sulphate ions measured during the electrolyses, which points out the importance of this plausible oxidation mechanism. The higher the concentration of SDS used for washing the soil, the higher is the amount of sulphate contained in the washing fluid 
and hence the higher is the effect expected of the mediated oxidation. This higher concentration explains the higher degradation rate observed in washing wastes with high ratio SDS/soil and that in spite of being much more contaminated, total depletion of pollutants is attained for a comparable electric charge passed.

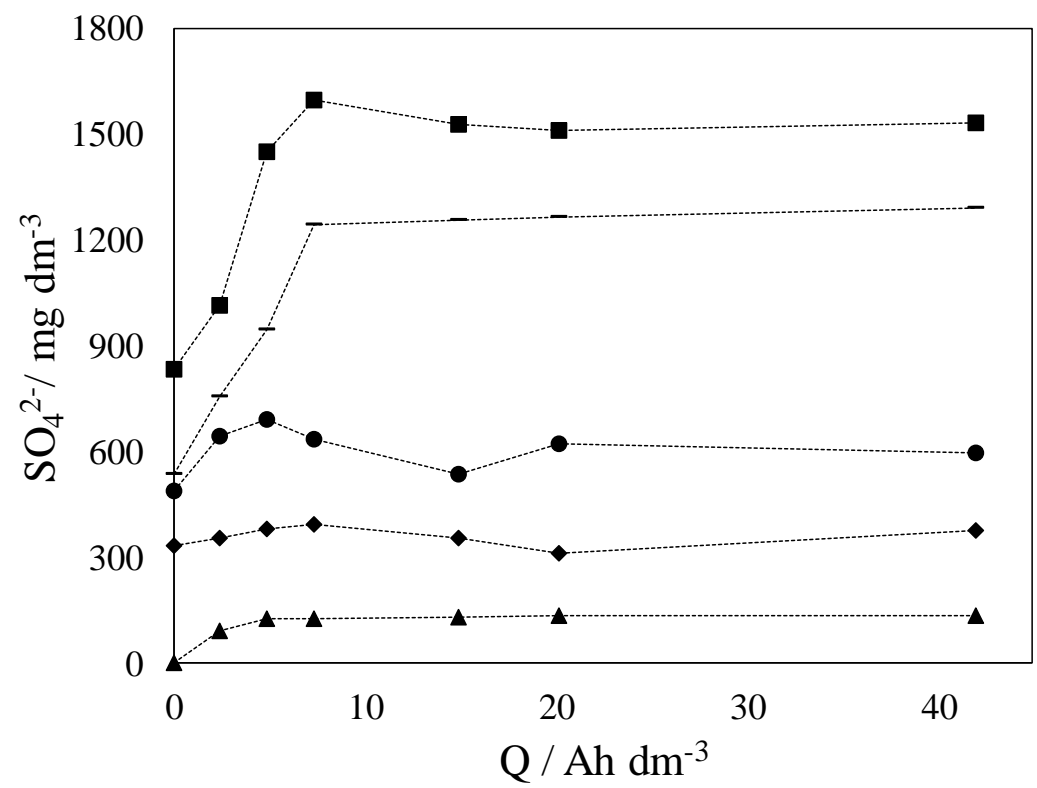

Figure 6. Sulphate ions produced during the electrolysis at $\mathrm{j}: 30 \mathrm{~mA} \mathrm{~cm}^{-2}$ of the effluents produced during soil washing with the following $[\mathrm{SDS}] /$ soil ratios: $0.5(\boldsymbol{\Delta}), 2.5(\bullet), 5.0(\bullet), 12.5(-)$ and $25.0(\mathbf{\square})$.

\section{Conclusions}

From this work, the following conclusions can be drawn:

- Combination of soil washing and electrolysis with diamond electrodes is a very efficient method for the depletion of atrazine from polluted soils

- Characteristics of the effluent produced in soil washing treatments are strongly influenced by the ratio surfactant /soil used. The higher the ratio, the lower the mean particle size, the more negative is the z-potential and the higher is the resulting waste COD and TOC. Maximum removals of atrazine can be attained with ratios as low as $0.5 \mathrm{~g}$ surfactant $/ \mathrm{kg}$ soil 
and no significant differences are obtained within the range 0.5-25.0 in the treated soil quality.

- Electrolysis with diamond electrodes of the waste produced in the soil washing is very efficient and attain the total depletion of pollutants by mineralization.

- Mean particle size decreases during the treatment down to zero and the surfactant is removed faster than the pesticide, indicating that oxidation mechanisms involves the attack of oxidants to the surface of micelles.

- Peroxosulphate produced by oxidation of the sulphate release during the oxidation of SDS plays an important role in the oxidation mechanisms of this type of pollutant.

\section{Acknowledgements}

The authors acknowledge funding support from the EU and Spanish Government through the MINECO Project CTM2013-45612-R, FEDER 2007-2013 PP201010 (Planta Piloto de Estación de Estación de Regeneración de Aguas Depuradas) and INNOCAMPUS. Brazil government by grant for $\mathrm{PhD}$ fellowship scholarship given for "doutorado sanduiche" under "Ciências sem Fronteiras" program to develop the experimental research at the UCLM-Spain is gratefully acknowledged.

\section{Literature cited}

[1] M.A. Rodrigo, N. Oturan, M.A. Oturan, Electrochemically Assisted Remediation of Pesticides in Soils and Water: A Review, Chemical Reviews, 114 (2014) 8720-8745.

[2] I. Sirés, E. Brillas, M.A. Oturan, M.A. Rodrigo, M. Panizza, Electrochemical advanced oxidation processes: today and tomorrow. A review, Environmental Science and Pollution Research, (2014).

[3] S. Bebelis, K. Bouzek, A. Cornell, M.G.S. Ferreira, G.H. Kelsall, F. Lapicque, C.P. de Leon, M.A. Rodrigo, F.C. Walsh, Highlights during the development of electrochemical engineering, Chemical Engineering Research \& Design, 91 (2013) 1998-2020.

[4] R. Lopez-Vizcaino, C. Saez, P. Canizares, M.A. Rodrigo, The use of a combined process of surfactant-aided soil washing and coagulation for PAH-contaminated soils treatment, Separation and Purification Technology, 88 (2012) 46-51. 
[5] C. Saez, R. Lopez-Vizcaino, P. Canizares, M.A. Rodrigo, Conductive-Diamond Electrochemical Oxidation of Surfactant-Aided Soil-Washing Effluents, Industrial \& Engineering Chemistry Research, 49 (2010) 9631-9635.

[6] R.D. Villa, A.G. Trovo, R.F. Pupo Nogueira, Soil remediation using a coupled process: soil washing with surfactant followed by photo-Fenton oxidation, Journal of Hazardous Materials, 174 (2010) 770-775.

[7] M.A. Rodrigo, P. Canizares, A. Sanchez-Carretero, C. Saez, Use of conductive-diamond electrochemical oxidation for wastewater treatment, Catalysis Today, 151 (2010) 173-177.

[8] M. Panizza, G. Cerisola, Direct And Mediated Anodic Oxidation of Organic Pollutants, Chemical Reviews, 109 (2009) 6541-6569.

[9] C.A. Martinez-Huitle, S. Ferro, Electrochemical oxidation of organic pollutants for the wastewater treatment: direct and indirect processes, Chemical Society Reviews, 35 (2006) 13241340.

[10] A.M. Polcaro, A. Vacca, M. Mascia, S. Palmas, Oxidation at boron doped diamond electrodes: an effective method to mineralise triazines, Electrochimica Acta, 50 (2005) 1841-1847.

[11] E. Brillas, I. Sires, M.A. Oturan, Electro-Fenton Process and Related Electrochemical Technologies Based on Fenton's Reaction Chemistry, Chemical Reviews, 109 (2009) 6570-6631.

[12] N. Oturan, E. Brillas, M.A. Oturan, Unprecedented total mineralization of atrazine and cyanuric acid by anodic oxidation and electro-Fenton with a boron-doped diamond anode, Environmental Chemistry Letters, 10 (2012) 165-170.

[13] I. Sires, E. Brillas, Remediation of water pollution caused by pharmaceutical residues based on electrochemical separation and degradation technologies: A review, Environment International, 40 (2012) 212-229.

[14] E. Isarain-Chavez, C. de la Rosa, C.A. Martinez-Huitle, J.M. Peralta-Hernandez, On-site Hydrogen Peroxide Production at Pilot Flow Plant: Application to Electro-Fenton Process, International Journal of Electrochemical Science, 8 (2013) 3084-3094.

[15] C.A. Martinez-Huitle, E. Brillas, Decontamination of wastewaters containing synthetic organic dyes by electrochemical methods: A general review, Applied Catalysis B-Environmental, 87 (2009) 105-145.

[16] A.K. Abdessalem, N. Bellakhal, N. Oturan, M. Dachraoui, M.A. Oturan, Treatment of a mixture of three pesticides by photo- and electro-Fenton processes, Desalination, 250 (2010) 450455.

[17] M.C. Edelahi, N. Oturan, M.A. Oturan, Y. Padellec, A. Bermond, K. El Kacemi, Degradation of diuron by the electro-Fenton process, Environmental Chemistry Letters, 1 (2003) 233-236.

[18] N. Oturan, M.A. Oturan, Degradation of three pesticides used in viticulture by electrogenerated Fenton's reagent, Agronomy for Sustainable Development, 25 (2005) 267-270.

[19] M.A. Oturan, I. Sires, N. Oturan, S. Perocheau, J.-L. Laborde, S. Trevin, Sonoelectro-Fenton process: A novel hybrid technique for the destruction of organic pollutants in water, Journal of Electroanalytical Chemistry, 624 (2008) 329-332.

[20] F.L. Souza, C. Saez, P. Canizares, A.J. Motheo, M.A. Rodrigo, Sonoelectrolysis of Wastewaters Polluted with Dimethyl Phthalate, Industrial \& Engineering Chemistry Research, 52 (2013) 9674-9682.

[21] F.L. Souza, C. Sáez, P. Cañizares, A.J. Motheo, M.A. Rodrigo, Coupling photo and sono technologies to improve efficiencies in conductive diamond electrochemical oxidation, Applied Catalysis B: Environmental, 144 (2013) 121-128.

[22] F.d.L. Souza, C. Saez, P. Canizares, A.d.J. Motheo, M. Andres Rodrigo, Using a new photoreactor to promote conductive-diamond electrochemical oxidation of dimethyl phthalate, Journal of Chemical Technology and Biotechnology, 89 (2014) 1251-1258.

[23] T. Dombek, D. Davis, J. Stine, D. Klarup, Degradation of terbutylazine (2-chloro-4ethylamino-6-terbutylamino-1,3,5-triazine), deisopropyl atrazine (2-amino-4-chloro-6-ethylamino- 
1,3,5-triazine), and chlorinated dimethoxy triazine (2-chloro-4,6-dimethoxy-1,3,5-triazine) by zero valent iron and electrochemical reduction, Environmental Pollution, 129 (2004) 267-275.

[24] G.R.P. Malpass, D.W. Miwa, S.A.S. Machado, P. Olivi, A.J. Motheo, Oxidation of the pesticide atrazine at DSA (R) electrodes, Journal of Hazardous Materials, 137 (2006) 565-572.

[25] G.R.P. Malpass, D.W. Miwa, R.L. Santos, E.M. Vieira, A.J. Motheo, Unexpected toxicity decrease during photoelectrochemical degradation of atrazine with $\mathrm{NaCl}$, Environmental Chemistry Letters, 10 (2012) 177-182.

[26] G.R.P. Malpass, G.R. Salazar-Banda, D.W. Miwa, S.A.S. Machado, A.J. Motheo, Comparing atrazine and cyanuric acid electro-oxidation on mixed oxide and boron-doped diamond electrodes, Environmental Technology, 34 (2013) 1043-1051.

[27] M. Mamián, W. Torres, F.E. Larmat, Electrochemical degradation of atrazine in aqueous solution at a platinum electrode, Portugaliae Electrochimica Acta, 27 (2009) 371-379.

[28] A.B. Ribeiro, J.M. Rodriguez-Maroto, E.P. Mateus, H. Gomes, Removal of organic contaminants from soils by an electrokinetic process: the case of atrazine. Experimental and modeling, Chemosphere, 59 (2005) 1229-1239.

[29] R. Lopez-Vizcaino, C. Saez, E. Mena, J. Villasenor, P. Canizares, M.A. Rodrigo, Electroosmotic fluxes in multi-well electro-remediation processes, Journal of Environmental Science and Health Part a-Toxic/Hazardous Substances \& Environmental Engineering, 46 (2011) 1549-1557.

[30] R. Lopez-Vizcaino, J. Alonso, P. Canizares, M.J. Leon, V. Navarro, M.A. Rodrigo, C. Saez, Electroremediation of a natural soil polluted with phenanthrene in a pilot plant, Journal of Hazardous Materials, 265 (2014) 142-150.

[31] R. Lopez-Vizcaino, J. Alonso, P. Canizares, M.J. Leon, V. Navarro, M.A. Rodrigo, C. Saez, Removal of phenanthrene from synthetic kaolin soils by electrokinetic soil flushing, Separation and Purification Technology, 132 (2014) 33-40.

[32] E. Jurado, M. Fernandez-Serrano, J. Nunez-Olea, G. Luzon, M. Lechuga, Simplified spectrophotometric method using methylene blue for determining anionic surfactants: Applications to the study of primary biodegradation in aerobic screening tests, Chemosphere, 65 (2006) 278-285.

[33] M.A. Rodrigo, P.A. Michaud, I. Duo, M. Panizza, G. Cerisola, C. Comninellis, Oxidation of 4chlorophenol at boron-doped diamond electrode for wastewater treatment, Journal of the Electrochemical Society, 148 (2001) D60-D64.

[34] P. Canizares, J. Garcia-Gomez, C. Saez, M.A. Rodrigo, Electrochemical oxidation of several chlorophenols on diamond electrodes - Part I. Reaction mechanism, Journal of Applied Electrochemistry, 33 (2003) 917-927.

[35] P. Canizares, J. Garcia-Gomez, C. Saez, M.A. Rodrigo, Electrochemical oxidation of several chlorophenols on diamond electrodes: Part II. Influence of waste characteristics and operating conditions, Journal of Applied Electrochemistry, 34 (2004) 87-94.

[36] S. Velazquez-Pena, C. Saez, P. Canizares, I. Linares-Hernandez, V. Martinez-Miranda, C. Barrera-Diaz, M.A. Rodrigo, Production of oxidants via electrolysis of carbonate solutions with conductive-diamond anodes, Chemical Engineering Journal, 230 (2013) 272-278.

[37] K. Serrano, P.A. Michaud, C. Comninellis, A. Savall, Electrochemical preparation of peroxodisulfuric acid using boron doped diamond thin film electrodes, Electrochimica Acta, 48 (2002) 431-436.

[38] P. Canizares, C. Saez, A. Sanchez-Carretero, M.A. Rodrigo, Synthesis of novel oxidants by electrochemical technology, Journal of Applied Electrochemistry, 39 (2009) 2143-2149. 